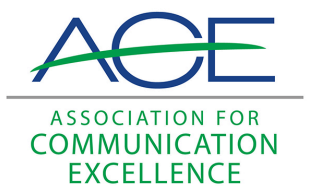

Journal of Applied Communications

\title{
Enjoyment and Information Gain in Science Articles; A Way to Reach Minorities: Multicultural Awareness; A Longitudinal Task of the Selective Exposure Hypothesis; Dakota Farmers and Ranchers Evaluate Crop and Livestock Surveys
}

Larry Meiller

John Fett

Follow this and additional works at: https://newprairiepress.org/jac

(c) $($ ) (2) (2)

This work is licensed under a Creative Commons Attribution-Noncommercial-Share Alike 4.0 License.

\section{Recommended Citation}

Meiller, Larry and Fett, John (1980) "Enjoyment and Information Gain in Science Articles; A Way to Reach Minorities: Multicultural Awareness; A Longitudinal Task of the Selective Exposure Hypothesis; Dakota Farmers and Ranchers Evaluate Crop and Livestock Surveys," Journal of Applied Communications: Vol. 63: Iss. 1. https://doi.org/10.4148/1051-0834.1807

This Review is brought to you for free and open access by New Prairie Press. It has been accepted for inclusion in Journal of Applied Communications by an authorized administrator of New Prairie Press. For more information, please contact cads@k-state.edu. 
Enjoyment and Information Gain in Science Articles; A Way to Reach Minorities: Multicultural Awareness; A Longitudinal Task of the Selective Exposure Hypothesis; Dakota Farmers and Ranchers Evaluate Crop and Livestock Surveys

\begin{abstract}
Reviews of "Enjoyment and Information Gain in Science Articles," by Alan Hunsaker; "A Way to Reach Minorities: Multicultural Awareness," by Benjamin Yep and Marynell Hollenbeck; "A Longitudinal Task of the Selective Exposure Hypothesis," by Michael A. Milburn; and Dakota Farmers and Ranchers Evaluate Crop and Livestock Surveys, by Calvin Jones, Paul Sheatsley and Arthur Stinchcombe.
\end{abstract}


M eiller and Fett: Enjoyment and Information Gain in Science Articles; A Way to Reac

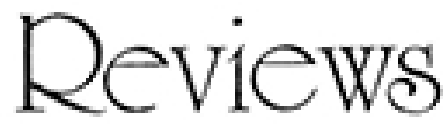

"Enjoyment and Information Gain in Science Articles. Alan Hunsaker, Journalism Quarterly, autumn, 1979. Vol. 56:3.

One problem plaguing Extension writers everywhere is how to get the scientist to agree to accept a more popular version of his or her research. Somehow. scientists fear their findings will be misinterpreted if they are made readable for the average person. Hunsaker's research offers the science writer some ammunition when confronting the dubious scientist. He essentially looked at the question of whether a science writer can convert dull journal reading into enjoyable magazine or newspaper articles without sacrificing authenticity. He hypothesized that skilled science writing can increase reader enjoyment without occasioning a decrease in information-gain.

To test this. Hunsaker selected a formal journal article and drafted two other articles based upon the source article. One was modeled on a "typical" Science News article, as defined by the mean scores for a sample of seven Science News articles on each of 18 contextual variables. Because Science News articles are generally "popularized," he hypothesized that this would be the most enjoyable article according to reader reports. The second article was modeled on a typical Science article. The author hypothesized that this article would be more enjoyable to read than the original journal article, but not as enjoyable as the less formal Science News version.

The three articles were randomly distributed among 
71 community college students. with each student receiving one article. Subjects were given 15 minutes to read the article and then were asked to fill out a questionnaire which contained both "feeling" and "information" questions.

Two points are worth noting from this study. The first is that reader enjoyment varied as a function of the type of writing. As hypothesized. enjoyment increased as the article became more popularized. The second point is that increased reader enjoyment does not necessarily result in decreased reader information gain. There was no significant difference in correct answers to questions from the three articles. The study shows it is possible to present science information in a form that lay people will read without sacrificing authenticity.

Larry Meiller. University of Wisconsin

\section{"A Way to Reach Minorities: Multicultural Aware-} ness." Benjamin Yep and Marynell Hollenbeck, Journal of Extension. March/April. 1979.

The authors of this article contend that Extension professionals and other human service organizations may unintentionally be imposing their own cultural be: liefs and practices on clientele with different cultural aspirations. To help professionals better work with minorities. the authors have identified three "intercultural lifestyles" practiced by racial minorities in this country and suggest alternatives for working with the differing groups.

Yep and Hollenbeck say three basic intercultural lifestyles are practiced by minorities: (1) cultural assimilation. (2) cultural pluralism, and (3) cultural separation. Minorities in the cultural assimilation group strive to become "totally Americanized" and adopt the beliefs. values, practices and language of the dominant American culture. These people tend to reject their traditional cultural background and their associations with other people from the culture. In the second. cultural pluralism, the person tries to be bicultural and live in both cultural environments. In the third lifestyle. cultural separation, the minority person strongly identifies with his or her traditional cultural heritage and rejects the

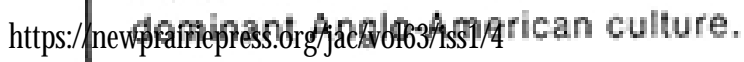


M eiller and Fett: Enjoyment and Information Gain in Science Articles; $A$ Way to Reac

The authors conclude that at present. most racial minority people participating in Extension committees and programs are from the cuiturally assimilated group. Because of similarities of beliefs. Extension staff tends to feel "most comfortable" working with these people, since their interests are similar. Extension people do not effectively reach the other groups because of cultural and language differences. The authors say that to reach these two racial minority audiences effectively, Extension needs to retrain existing staff and/or hire new staff who are bilingual and bicultural.

Larry Meiller. University of Wisconsin

\section{"A Longitudinal Task of the Selective Exposure Hy-} pothesis." Michael A. Milburn, Public Opinion Quarterly, Vol. 43:4, winter 1979, 507-17.

The predominant position in the literature on the effects of mass media campaigns is that most attempts at changing attitudes and behavior through the media will be unsuccessful. The argument is that it may be possible to increase knowledge, but attitudes are highly resistant to change, and the media's effects are limited by selective exposure, retention and perception. However, this view was challenged by Mendelsohn (1973) whose arguments found emperical support in the Stanford's mass media campaign on heart disease prevention (Maccoby and Ferquhar, 1975, 1976).

The Stanford study results showed a relatively high correlation between campaign exposure and health knowledge. But that does not necessarily mean campaign success. Perhaps people with higher knowledge and interest on a topic simply pay more attention to additional campaign information on the same topic. Using crossleg analysis and partial regression analysis on the Stanford data, Milburn found that exposure to the media campaign caused increased health knowledge. This increased health knowledge, in turn, led to more positive attitudes toward health practices. He found no evidence of selected exposure effects.

Mendelsohn, H., "Some Reasons Why Information Campaigns Can Succeed, " Public Opinion Quarterly, Vol. 37, No. 1 (1973). 
Maccobyrnal of Applied Communications, Vol. 63, Iss. 1 [1980], Art. 4 and W. Ferquhar. "Communication for Health: Unselling Heart Disease," Journal of Communication, Vol. 25 , No. 3 (1975), 114-26.

"Bringing the California Health Report Up to Date," Journal of Communication, Vol. 26, No.1 (1976). 56-57.

John Fett. University of Wisconsin

Dakota Farmers and Ranchers Evaluate Crop and Livestock Surveys. Calvin Jones, Paul Sheatsley and Arthur Stinchcombe, National Opinion Research Center. Report No. 128, 1979, Chicago, Illinois.

The practice of surveying clientele to determine how well they are being served seems to have increased greatly in recent years. The authors of this book have succeeded in providing us with much useful information related to one of our primary clientele-farmers.

The authors conducted a telephone survey of a sample of several hundred farmers in North and South Dakota. The survey was undertaken for the USDA Crop Reporting Board to learn how the USDA could improve participation in the 500 surveys it makes every year. The findings are certainly relevant to anyone conducting this type of work.

Almost half the operators said they were asked to participate in surveys too often. However, as the authors note, this response was not necessarily related to the number of requests operators reported receiving. In fact, those who were asked to participate most often were least likely to complain. Instead, complaints about the number of survey requests were much more strongly related to the belief that the surveys could not be trusted. served no useful purpose. hurt their profits. or mainly benefited competitors.

Farmers also were asked to speculate about why other farmers would refuse to participate in the crop and livestock surveys. Two answers were most prevalent. One related to privacy-farmers said the surveys ask for too much personal information, delve into operators' decisions that are not the government's business, and elicit information that might be used against https://newprairiepress.org/jac/vol63/issi/4 4 ally. The other answer related to 
Meller and Fett: Enjoyment and Information Gain in Science Articles; A Way to Reac the effects of the government reports. Producers felt the reports depress prices and are exploited by interests opposed to producers. The authors conclude that. participation rates depend more on general attitudes than on the characteristics of a particular survey.

Of additional interest in this book is the amount of information concerning farmers' media habits. The authors found that farmers' use of periodical literature for livestock information (magazines. journals and newsletters) declines monotonically with age. Two thirds of the operators under 40 cited this source. as compared to less than half of those 60 or older. Mass media use was not differentiated by age, except that the youngest operators were most likely to mention using television reports, while the oldest were least likely to.

All in all, this book offers a wealth of information for information specialists and I would recommend ACE members take a careful look at it.

Larry Meiller. University of Wisconsin 